\title{
Measuring Actions for Nature-Development and Validation of a Pro-Nature Conservation Behaviour Scale
}

\author{
Lea Barbett $^{1, * \mathbb{D}}$, Edward J. N. Stupple ${ }^{1}$, Michael Sweet ${ }^{2}{ }^{\oplus}$, Malcolm B. Schofield ${ }^{1}$ \\ and Miles Richardson ${ }^{1}[\mathbb{D}$ \\ 1 Human Sciences Research Centre, University of Derby, Derby DE22 1GB, UK; \\ e.j.n.stupple@derby.ac.uk (E.J.N.S.); m.schofield@derby.ac.uk (M.B.S.); m.richardson@derby.ac.uk (M.R.) \\ 2 Environmental Sustainability Research Centre, University of Derby, Derby DE22 1GB, UK; \\ m.sweet@derby.ac.uk \\ * Correspondence: 1.barbett@derby.ac.uk
}

Received: 18 May 2020; Accepted: 11 June 2020; Published: 15 June 2020

\begin{abstract}
Scientists have classed the ongoing decline in biodiversity-caused by humans-as a mass extinction. To mitigate the consequences of this extinction, immediate action is of the utmost importance. However, effective ways of promoting pro-nature conservation behaviours to preserve and enhance biodiversity require better understanding and measurement. Thus, a reliable and valid measurement tool is needed. While there are measurement tools for general pro-environmental behaviours, as of yet, no measure of behaviours that specifically promote biodiversity exists. Here, we present such a tool: the Pro-Nature Conservation Behaviour Scale (ProCoBS), a psychometrically validated questionnaire scale measuring active behaviours that specifically support the conservation of biodiversity. An item pool developed through consultation with wildlife and biodiversity experts was subjected to psychometric scale development analyses. Data from 300 participants were used to develop the 18-item ProCoBS long form, as well as an 8-item short form. A latent variable model with four factors (Individual Engagement, Social Engagement, Planting, and Wildlife) was identified. In a second study, a subset of 250 of the original participants answered the questionnaire again, in addition to related psychological constructs. The data were used to assess test-retest reliability and construct validity. Results showed that the scale and its short form were reliable (full scale: $\alpha=0.893$, short form: $\alpha=0.825$ ) and valid. In a third study, a representative sample of 1298 adults in the UK completed the short form. Confirmatory Factor Analysis demonstrated a good fit for all factors, indicating that the ProCoBS is a psychometrically robust measure. The ProCoBS provides the definitive, much needed tool for measuring conservation behaviours. This will enhance research and impact practical work in the conservation domain for a sustainable future. A cross-cultural examination of the scale is still needed.
\end{abstract}

Keywords: psychometrics; nature conservation; pro-nature conservation behaviours; civil action; gardening; pro-environmental behaviours

\section{Introduction}

Society today is confronted with a range of environmental challenges. Human population growth and consumption behaviours all over the world have caused many threats to our planet and all its inhabitants. The most topical of these challenges is climate change, which has become a widely known issue. Many scientific disciplines have addressed climate change, and it is a driver for new policies and legislation all over the world, an example of which can be found in [1]. However, there is another, equally dangerous, threat to a sustainable future: biodiversity loss. Biodiversity on our 
planet is decreasing at an alarming rate, which will have a grave impact on the environment, as well as on humans [2]. However, this is less widely known and less covered in the media than climate change-related issues [3].

Human behaviours are the main cause of the ongoing decline in biodiversity. We, as a society, need to change our behaviours to reduce the current harm we are causing and to actively support the restoration of ecosystems and wildlife [4]. There are various behaviours that individuals can undertake to support and protect local, regional, national, and international wildlife, as well as ecosystems as a whole [5]. These actions can be classed as pro-nature conservation behaviours. Similar to the general media coverage of climate change in comparison to biodiversity loss, there is a large body of research on general pro-environmental behaviours but far less research on pro-nature conservation behaviours. In order to change this and to create an understanding of pro-nature conservation behaviours, with the aim of effectively encouraging the general public to engage in them, a reliable and valid measurement tool is needed. This paper will introduce the Pro-Nature Conservation Behaviour Scale (ProCoBS), which is a psychometrically validated measure based on expert ratings of the ecological impact of the included behaviours.

The decline in biodiversity affects a wide variety of species, but particularly those classed as wild. Recently, a report by The Intergovernmental Science-Policy Platform on Biodiversity and Ecosystem Services (IPBES) [2] highlighted the fact that up to 1 million species are threatened with extinction, and only $13 \%$ of oceans and $23 \%$ of land can still be classed as wilderness. One of the most typically reported examples of the gravity of biodiversity loss is the decline of wildlife. The Living Planet Report [6] revealed a $60 \%$ decrease in wildlife populations between 1970 and 2014. In particular, amphibians ( $>40 \%$ of recorded species critically endangered [2]) and pollinating or pest-controlling insects (e.g., $75 \%$ decline in the biomass of flying insects in Germany [7]) will have significant impacts on how ecosystems function [8]. Not only is this devastating on a biodiversity and ecosystem level, but also regarding the impact that such loss or decline has on a number of "services" that are essential to human living and well-being [9]. We are now within the sixth documented mass extinction event-one which has been solely and uniquely accredited to anthropogenic (human-induced) forces [10]. Researchers found that, even when using conservative assumptions, the rates of vertebrate decline can be classed as a mass extinction [10]. Primarily, land use associated with the processes of urbanisation and agriculture contribute to the destruction of habitats [11,12].

Although this paints a depressing picture, the fact that these declines are accredited to human-induced actions means we can act and attempt to reverse or halt the current trends. Furthermore, people are becoming more aware of, and therefore more concerned about, the impacts of wildlife extinctions. However, despite an increase in people reporting a level of concern about environmental issues, their actions are often inconsistent with these thoughts. Research has shown that $72 \%$ of people report a gap between attitudes, intentions, and actions, even without situational barriers [13]. This is known as the Value-Action gap [14]. Psychological theory can be used to understand the reasons for this and to achieve effective communications and interventions [15]. A reliable and valid measure of pro-nature conservation behaviours is therefore an essential first step to explore the psychological determinants of the value-action gap and to evaluate behavioural interventions. There is extensive research on general pro-environmental behaviours in environmental psychology. Over 40 scales have been developed to measure these behaviours [16]. They are often positive inactions, with the goal of minimising a negative impact on the environment [17]. Usually, this relates more closely to general environmental issues (e.g., choosing public transport over a car, or aiming to reduce one's carbon footprint) [16]. As of yet, no scale has been developed to measure active behaviours that specifically support nature conservation (i.e., pro-nature conservation). Thus, while there are a range of options available to researchers seeking to measure behaviours which may slow climate change or reduce pollution, there is currently no specific measure that captures behaviours that specifically aim to restore the natural environment and increase biodiversity. 
Indeed, conservation practitioners and researchers have shown interest in these more specific behaviours, which are often missed in other scales. Several studies clearly express a difference between pro-environmental and pro-nature conservation behaviours [18-20]. Research supported by the Royal Society for the Protection of Birds (RSPB), one of the world's largest conservation organisations, referred to this exactly and stated that there are two clear types of behaviours: "pro-environmental behaviours focused on resource use and energy saving, and pro-nature behaviours focused on wildlifeoriented actions" [18]. This distinction can also be found in research done in collaboration with, and reports published by, other conservation organisations (e.g., as explored in [20]). These reports show a strong desire from conservation practitioners for a behavioural measure more specific to nature conservation. In fact, a study conducted in collaboration with the Wildlife Trusts in the United Kingdom lamented the lack of a measurement tool for nature conservation-specific behaviours [21]. This lack of focus on more biodiversity-specific behaviours has also been pointed out from an academic point of view by Prévot and colleagues [5]. Some research has considered conservation-related behaviours and their determinants, as well as possible communications and interventions $[5,20]$. Each study, however, assesses different behaviours, and not all studies consider the ecological impact of the behaviours they assess. In addition, a variety of different terms have been used to describe these behaviours, from pro-nature [18], over pro-biodiversity practices [22], to conservation engagement [23]. For scientific research into pro-nature conservation behaviours, validated and established measurement tools play a key role [24]. The Value-Action gap in the specific area of conservation-directed behaviours needs to be studied in more detail, and, therefore, the development of a validated measurement tool is essential. The following paragraphs define pro-nature conservation behaviours and introduce some ecologically impactful types of behaviour that formed the base of the ProCoBS.

To define pro-nature conservation behaviours, the term "nature conservation" needs clarification. While the term "conservation" often refers to nature conservation, it can also refer to the conservation of resources (e.g., water) or built heritage. In fact, the term "conservation behaviours" is often used to refer to general environmental behaviours or resource conservation-specific behaviours [25]. Thus, the term "nature conservation" is used in this paper. This is a widely used term by leading nature conservation organisations, such as the RSPB (www.rspb.org.uk/our-work/conservation/) and

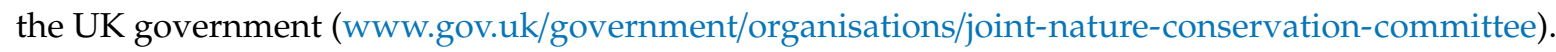
These organisations see nature conservation as a response to the decline of biodiversity and seek to protect species, particularly wildlife, and habitats. Therefore, pro-nature conservation behaviours are positive actions that aim to support these conservation goals and have an impact on nature conservation. Both the aim to support nature conservation and the impact of the actions are important to consider. Stern [26] differentiates between two "realities" of behaviour: a subjective reality, which refers to behaviours as the means for people to achieve a goal, and an objective reality, which refers to the meaning of the behaviour and its consequences. Kaiser and Wilson [27] argue that researching environmental behaviours that are not goal-directed and, therefore, are not tapping into the subjective reality component, will not be psychologically meaningful. In contrast, behaviours with good intentions but no real impact on the ecosystem or biodiversity are of no interest to conservation practitioners. Therefore, when developing a scale measuring pro-nature conservation behaviours, it is important to address both realities in an inter-disciplinary manner. The scale should be tested using psychometric methods, but the behaviours must be based on conservation biology and ecology, and reviewed by academic experts and conservation practitioners, to insure their impact. Research from a stratified sample of 4960 UK residents has revealed that pro-nature conservation behaviours are distinct from pro-environmental behaviours on a psychological level [19]. Furthermore, many pro-environmental behaviour scales do not include the kind of behaviours typically examined by applied behavioural nature conservation research (e.g., as detailed in $[16,28])$.

Various conservation organisations already encourage some behaviours for wildlife and biodiversity conservation. However, some of these behaviours fall under pro-environmental behaviours, and for others their impact on biodiversity needs to be considered. Conservation behaviours for 
the scale were chosen based on research in the field of conservation biology and ecology, as well as opinions of subject matter experts. Ecologists have started capitalising on green spaces in urban areas as important wildlife habitats [29]. A large proportion of these green spaces are made up of private gardens, thus giving garden owners the possibility of supporting wildlife [30]. Simple changes to domestic gardens have the power to increase native biodiversity, making gardens an important tool for nature conservation [31]. Many conservation organisations suggest a variety of gardening behaviours (e.g., those detailed in [32]). These behaviours can include, for example, planting a tree or maintaining a wildlife friendly pond [31]. However, not everyone has access to a garden, especially people from lower income groups. This does not mean that those people cannot engage in pro-nature conservation behaviours. Indeed, behaviours regarding political participation (for example) are more widely accessible and can have an important influence on public policy decision-making and social change [33]. These behaviours do not only concern urban greenspaces but often wider nature conservation issues. For example, Prévot and colleagues [5] included voting intentions, based on candidates' positions on conservation issues in their assessment of conservation practices, and highlighted its importance amongst other individual commitments [34]. Pro-nature conservation behaviours may be motivated by, and related to, a variety of psychological and behavioural constructs. These can be used to test for construct validity of a scale measuring pro-nature conservation behaviours. They will be introduced in the following paragraphs.

Due to the lack of substantial literature on pro-nature conservation behaviours, not all chosen variables were based on research in this area. Some were based on research regarding pro-environmental behaviours. The constructs of self-efficacy, connectedness to nature, ecological worldview, and well-being were central to our development of the ProCoBS. Further pro-environmental behaviours were also included in the validation measures.

Self-efficacy is a widely used key concept in explaining a variety of behaviours [35]. It is defined as a person's confidence in their ability to solve a problem or accomplish a task [36] and affects their actual ability to achieve the goal [37]. As such a widely used concept, self-efficacy has also been applied to pro-nature conservation behaviours; perceived self-efficacy to protect biodiversity was found to be highly correlated to behaviour and behavioural intent [38]. Thus, the ProCoBS should correlate with perceived self-efficacy.

Recently, emotions have become an important focus of research on the Value-Action gap. Connectedness to nature is a psychological construct of an individual's affective relationship to nature $[39,40]$. Nature connectedness has been found to outperform other predictors of pro-environmental behaviour [41], which was confirmed by recent meta-analyses [42,43]. We predict that connectedness to nature will be similarly important in conservation behaviours. It may not only act as a predictor. Spending time in nature through wildlife-friendly gardening could evoke a feeling of connectedness to nature, as it constitutes a compassionate behaviour towards nature. Compassion towards nature has been found to be a pathway to nature connectedness [44].

Another key variable in research on pro-environmental behaviours is the ecological worldview. An individual's ecological worldview consists of their primitive beliefs about the roles nature and humans play for one another [45]. Ecological worldview is commonly measured with the New Environmental Paradigm (NEP [46]). This construct has been positively related to environmental behaviours [47]. Furthermore, Gkargkavouzi, Halkos, and Matsiori [48], found that ecological worldview and connectedness to nature were especially predictive of environmental behaviours, falling under the dimensions of civic actions, recycling, household behaviours, and consumerism. Conservation behaviours include civic actions and behaviours conducted at home and may, therefore, be predicted by those two constructs in particular.

Bridging the Value-Action gap in conservation behaviours may not only have a positive impact on ecosystems. Well-being benefits to those who engage in conservation behaviours have been found. These benefits could be related to several aspects of a pro-conservation behaviour intervention. Volunteering with conservation organisations can lead to the significant improvement of mental 
well-being [49]. Furthermore, caring for nature is a pathway to nature connectedness [44], which itself has well-being benefits [50]. More generally, just spending time in nature can positively affect stress relief and mood [51]. Engaging in pro-nature conservation behaviours, which include volunteering with conservation organisations, as well as activities taking place outdoors in nature, might, therefore, be related to well-being.

This study developed and validated a questionnaire scale to measure pro-nature conservation behaviours (ProCoBS) according to the current standard for psychometric scale development [52]. All items on the scale were based on their ecological impact and were reviewed by a panel of Subject Matter Experts (SMEs) to ensure content validity. The resulting item pool was administered to a sample of the general UK population. The item list was reduced using internal consistency tests to achieve reliability and an exploratory factor analysis (EFA) was executed to examine dimensionality and further shorten the item list, leading to the finished ProCoBS. Test-retest reliability and construct validity were investigated in a second study. One month after the first study, the ProCoBS was administered to a subsample of the original participants, in conjunction with measures of possibly-related constructs. Based on the existing literature, as outlined above, we hypothesised that pro-nature conservation behaviours are related to pro-environmental behaviours, nature connectedness, ecological worldview, self-efficacy, and well-being. A third study was therefore conducted to complete a confirmatory factor analysis (CFA) on the factor structure that emerged from the EFA.

\section{Materials and Methods}

\subsection{Item Generation}

For item generation, a Subject Matter Expert (SME) review, according to Lawshe [50], was used. A longlist of behaviours (37 items), deemed to be linked to conservation, based on a literature review, was initially generated. Materials included scientific peer-reviewed published studies found through search words, such as conservation behaviours, nature conservation behaviours, and biodiversity conservation behaviours. Furthermore, grey literature, which includes behaviours encouraged by big conservation organisations, as well as calls for action by conservation activists, was reviewed. The 37-item list, shown in Appendix A, was then sent to the SMEs to rate each item as useful or not. The SMEs were found through their academic work in the field or through their work with prominent conservation organisations. Following a request via direct contact, prominent conservation organisations, and social media, 25 SMEs responded to this list. Of them, 24 were from the UK and 1 was from Germany. The SMEs were from a variety of academic and practice-based conservation backgrounds, which they were asked to explain before starting the SME review. For example, they reported working in conservation science, conservation biology, and ecology on the academic side. On the practitioner side, the SMEs included, for example, scientific advisors for conservation organisations, field conservation project leaders, and outreach specialists. First, the aims of the scale development were explained to the SMEs and then they were asked to indicate whether they thought each behaviour belonged on an impact-based scale measurement using "yes", "no", and "I don't know" responses. Lawshe's [53] Critical Validity Ratio (CVR) was calculated for each item. Items with CVRs below the critical value set by Lawshe [53] were discarded, except for five, which only fell marginally below the critical value. This left 25 items on the list. Out of these items, 11 were behaviours focused around gardening (hereafter referred to as gardening behaviours) and 14 were behaviours that people without access to a garden can engage in (hereafter referred to as non-gardening behaviours).

\subsection{Study One: Scale Development}

\subsubsection{Participants}

A convenience sample of 300 participants living in the UK were recruited via Prolific Academic. This number of participants was chosen according to a number of guidelines considering both 
item-number-dependent sample size guidelines (item number $\times 10$ [54]) and item-number-independent sample size guidelines, proposing 300 participants [55]. Their ages ranged from 18 to 69 years, with the mean age at 34.4 years, $(\mathrm{SD}=10.53)$. In total, $71 \%$ of the participants were female and $29 \%$ were male. Out of the 300 Participants, 225 (75\%) had access to a garden.

\subsubsection{Materials and Procedure}

The study was granted ethical approval by the University of Derby. All participants gave informed consent and were debriefed. They were also informed before participation that, after a month, there would be a follow-up study to be completed by participants who had completed the first study. The participants answered an online questionnaire, which included demographics (age and gender) and the 25-item behaviour questionnaire. Participants were asked to indicate how often they engaged in each behaviour on a 7-point Likert scale based on Vagias [56] (1-Never, 2-Rarely, 3-Occasionally, 4-Sometimes, 5-Frequently, 6-Very Frequently, 7-Always).

Participants first answered the non-gardening items, followed by the question of whether they had access to a garden at home, either via a community garden or if they were landowners. If they indicated that they had access to a garden or land, they completed the gardening items and then the demographic questions. Those participants who did not have access to a garden or land did not complete the gardening items. Thus, for those participants only a non-gardening score could be calculated. Scores for the whole scale were only calculated for participants answering both parts to avoid a difference in whole scores between those who answered the gardening questions and those who did not. Due to the difficulty in comparing the impact of behaviours directed at societal change with more direct behaviours, such as creating habitats in one's garden, no weighting based on impact was given to the items, since the SME review had assured that all of the items used were seen as impactful by experts in the field. The data were analysed using internal consistency tests and an exploratory factor analysis to reduce and refine the items and determine factors within the scale. The data were also used to create a short form of the resulting scale.

\subsection{Study Two: Test-Retest Reliability and Validity of the New Measure and Its Subscales}

\subsubsection{Participants}

All participants from study one were approached with the survey for study two. In total, 225 out of the original 300 participants $(74.33 \%)$ from the first study answered this second study. The age range was similar, 19-69, with a slightly increased mean of $35.43(\mathrm{SD}=10.52)$. Furthermore, the same sex ratio occurred (71\% female, 29\% male). Overall, 164 participants (equalling $72.89 \%$ ) had a garden.

\subsubsection{Materials and Procedure}

Participants who had completed study one were contacted via their Prolific account number. All answers were collected via an online questionnaire. The same demographic questions and pro-nature conservation behaviour items were administered in study two. In addition to these, we included a variety of scales measuring constructs that were hypothesised to be related to pro-nature conservation behaviours.

To assess nature connectedness, two scales were utilised: the Inclusion of Nature in Self (INS) scale and the Nature Relatedness Scale (NRS) [40,57]. The INS scale is a single-item measure [57], which uses graphic representations of "self" and "nature" as two circles. Participants selected one of seven choices where the circles had different levels of overlap. This scale is a cognitive measure of the construct of nature connectedness [58]. In contrast, the six item NRS focuses on affective aspects of the construct using a 5-point Likert scale, ranging from "disagree strongly" to "agree strongly". Items include, for example, "I feel very connected to all living things and the earth" [40].

The New Ecological Paradigm (NEP) scale was also utilised to measure environmental worldview [46]. This scale contains 15 items, such as "humans have the right to modify the natural 
environment to suit their needs", which are rated on a 5-point Likert scale (from 1 = Strongly agree to $5=$ Strongly disagree).

To compare conservation behaviours with general environmental behaviours, we utilised the 19-item Pro-environmental Behaviour Scale (PEBS [16]). The scale covers four sections, which use seven different response scales. For example, the first section, "Conservation" (of energy and water), includes seven items (e.g., "How often do you turn off the lights when leaving the room?").

Well-being was measured using the WHO Wellbeing Index (WHO-5) [59]. WHO-5 enquires about participants' feelings in the past two weeks using 5 items, such as "I have felt calm and relaxed". Items were rated on a 6 -Point Likert scale $(1=$ All of the time to $6=$ At no time).

Finally, the 10-item Generalised Self-Efficacy scale (GSE; [60] was administered. Example items included: "I can always manage to solve difficult problems if I try hard enough". Items were rated on a 4-point Likert scale from "not at all true" to "exactly true".

The data were analysed using internal consistency tests and correlations between test and retest data, as well as retest data and related scales for both the long form and short form scales, as developed in study one. Furthermore, a regression analysis was used to examine how far the related constructs explained pro-nature conservation behaviours.

\subsection{Study Three: Confirmatory Factor Analysis}

\subsubsection{Participants}

Using a YouGov survey, responses from a stratified sample, representative of the British population, of 1298 adults were collected. Of these adults, $47.2 \%$ of participants were male, $52.8 \%$ were female. Participants were aged $16-55+$, with $51 \%$ of participants being between 25 and 54 years old. In total, $17.1 \%$ of participants reported having no access to a garden at home or through other opportunities (e.g., allotment, community garden).

\subsubsection{Materials and Procedure}

Participants were given the 8-item short form of the ProCoBS, as shown below. They rated each item on a Likert-scale from 1 (Never) to 7 (Always). The data were then used for a Confirmatory Factor Analysis (CFA).

\section{Results}

\subsection{Study One}

Item-total correlations were calculated for each item, and all items with $r<0.3$ were excluded (as suggested by [54]). Thus, one item was excluded due to low item-total correlations in the non-gardening behaviours, and two items were excluded from the gardening behaviours. After their removal, the item-total correlations for the full list were calculated and all remaining items had a correlation of $r>0.3$. This left 22 items (9 gardening and 13 non-gardening) for inclusion in the factor analysis.

\subsubsection{Factor Analysis}

Kolmogorov-Smirnoff and Shapiro-Wilk tests for the remaining items revealed violations of normality for several items. Thus, Principal Axis Factoring (PAF) using a promax rotation with Kaiser normalisation was chosen for the factor analysis. First, gardening and non-gardening items were examined separately. Following this, PAF was performed for the full list of remaining items. The Kaiser-Mayer-Olkin Measure and Bartlett's test of Sphericity suggested factorability (KMO $=0.886$, $\left.\chi^{2}=2293.226, \mathrm{df}=231, p<0.001\right)$. Furthermore, low off-diagonal anti-image correlation values supported this [61]. A factor loading threshold of 0.45 was set, based on Comrey and Lee [62]. After the removal of two items falling below this threshold, the two subscales were examined separately using 
only the remaining items. The Kaiser-Meyer-Olkin (KMO) measure for both suggested that the data were suitable for a factor analysis (gardening $\mathrm{KMO}=0.863$, non-gardening $\mathrm{KMO}=0.857$ ). Furthermore, the Bartlett's test for Sphericity was significant for both (gardening: $\chi^{2}=961.948, \mathrm{df}=36, p<0.001$; non-gardening: $\chi^{2}=1377.199, \mathrm{df}=55, p<0.001$ ). Both had low off-diagonal anti-image correlation values, a further indicator of suitability for factor analysis.

For the gardening subscale, no items were below the threshold. For non-gardening behaviours, one item with factor loadings below the threshold of 0.45 was removed from the non-gardening list, as well as the full list.

After running a Factor Analysis on the now remaining items for the full scale, one further item from the non-gardening behaviours had a factor loading below the 0.45 threshold and was removed.

Principal Axis Factoring with promax rotation (with Kaiser normalisation) was run for the combined item list ("ProCoBS"; 18 items), as well as the two separate item lists (9 items each). Factors were extracted based on eigenvalues $\geq 1$ and the scree plots. The separate lists each had two factors and the ProCoBS had four factors, splitting into the same factors as the two separate lists, as shown in Tables 1-3. The non-gardening behaviours were labelled "Civil Action" with the two factors "Individual Engagement" and "Social Engagement. The gardening items were labelled "Gardening", splitting into the two factors "Planting" and "Wildlife". These four factors explained the 64.77\% variance of the complete scale. When considering the Civil Action Subscale separately, the two factors explained the $63.67 \%$ variance. The two factors found when examining the gardening behaviours by themselves explained the $63.89 \%$ variance.

Table 1. Pattern matrix of rotated factor loadings for the full ProCoBS (showing all factor loadings $\geq 0.45$ ).

Eigenvalues are reported in brackets behind the factor names.

\begin{tabular}{|c|c|c|c|c|}
\hline Item & $\begin{array}{c}\text { Individual } \\
\text { Engagement }(6.521)\end{array}$ & Planting (2.197) & $\begin{array}{c}\text { Organised } \\
\text { Engagement (1.855) }\end{array}$ & Wildlife (1.085) \\
\hline $\begin{array}{l}\text { I attend local council/local authority meetings } \\
\text { about nature conservation issues }\end{array}$ & 0.911 & & & \\
\hline When I see litter, I pick it up & 0.835 & & & \\
\hline $\begin{array}{l}\text { I get in touch with local authorities on nature } \\
\text { conservation issues }\end{array}$ & 0.798 & & & \\
\hline $\begin{array}{c}\text { I vote for nature or wildlife } \\
\text { conservation-friendly legislation in local or } \\
\text { national referendums/votes/etc. }\end{array}$ & 0.585 & & & \\
\hline $\begin{array}{l}\text { I vote for parties/candidates with strong } \\
\text { pro-nature conservation policies in elections }\end{array}$ & 0.528 & & & \\
\hline I plant pollinator-friendly plants & & 0.931 & & \\
\hline I plant plants with different flowering seasons & & 0.924 & & \\
\hline I plant native plants & & 0.795 & & \\
\hline I maintain plants with berries/fruits & & 0.471 & & \\
\hline $\begin{array}{l}\text { I volunteer with a conservation organisation } \\
\text { in habitat management work }\end{array}$ & & & 0.807 & \\
\hline $\begin{array}{l}\text { I volunteer with a conservation organisation } \\
\text { in another area not mentioned above (e.g., } \\
\text { fundraising, education, etc.) }\end{array}$ & & & 0.705 & \\
\hline I participate in organised clean-up events & & & 0.651 & \\
\hline $\begin{array}{l}\text { I sign petitions supporting nature } \\
\text { conservation efforts }\end{array}$ & & & 0.565 & \\
\hline $\begin{array}{l}\text { I leave an undisturbed/unmaintained area } \\
\text { for wildlife }\end{array}$ & & & & 0.780 \\
\hline $\begin{array}{l}\text { I avoid cutting/trimming hedges during bird } \\
\text { breeding season (March-July) }\end{array}$ & & & & 0.557 \\
\hline I avoid using insecticides & & & & 0.551 \\
\hline $\begin{array}{l}\text { I add log piles or other materials that can be } \\
\text { used as a home/shelter by wildlife }\end{array}$ & & & & 0.543 \\
\hline I provide food for wild animals, such as birds & & & & 0.462 \\
\hline
\end{tabular}


Table 2. Pattern matrix of rotated factor loadings for the Civil Action items (showing all factor loadings $\geq 0.45$ ). Eigenvalues are reported in brackets behind the factor names.

\begin{tabular}{ccc}
\hline Items & Individual Engagement (4.043) & Organised Engagement (1.687) \\
\hline $\begin{array}{c}\text { I attend local council/local authority meetings } \\
\text { about nature conservation issues }\end{array}$ & 0.902 & \\
\hline $\begin{array}{c}\text { When I see litter, I pick it up } \\
\text { conservation issues }\end{array}$ & 0.808 & \\
\hline $\begin{array}{c}\text { I get in touch with local authorities on nature } \\
\text { I vote for nature or wildlife conservation-friendly } \\
\text { legislation in local or national } \\
\text { referendums/votes/etc. }\end{array}$ & 0.769 & \\
\hline $\begin{array}{c}\text { I vote for parties/candidates with strong pro-nature } \\
\text { conservation policies in elections }\end{array}$ & 0.709 & 0.739 \\
\hline $\begin{array}{c}\text { I volunteer with a conservation organisation in } \\
\text { habitat management work }\end{array}$ & & 0.672 \\
\hline $\begin{array}{c}\text { I participate in organised clean-up events } \\
\text { I volunteer with a conservation organisation in } \\
\text { another area not mentioned above (e.g., } \\
\text { fundraising, education, etc.) }\end{array}$ & & 0.672 \\
\hline $\begin{array}{l}\text { I sign petitions supporting nature } \\
\text { conservation efforts }\end{array}$ & & 0.637 \\
\hline
\end{tabular}

Table 3. Pattern matrix of rotated factor loadings for the Gardening items (showing all factor loadings $\geq 0.45$ ). Eigenvalues are reported in brackets behind the factor names.

\begin{tabular}{ccc}
\hline Items & Planting (4.520) & Wildlife (1.230) \\
\hline I plant pollinator-friendly plants & 0.933 & \\
I plant plants with different flowering seasons & 0.927 & 0.800 \\
I plant native plants & 0.451 & 0.820 \\
I maintain plants with berries/fruits & & 0.568 \\
I leave an undisturbed/unmaintained area for wildlife & 0.563 \\
I avoid cutting/trimming hedges during bird breeding season (March-July) & & 0.558 \\
I avoid using insecticides & & 0.549 \\
\hline
\end{tabular}

\subsubsection{Reliability}

Cronbach's alpha was calculated to assess internal reliability. Reliability was high for the ProCoBS $(\alpha=0.893)$, the two separate scales (Civil Action $\alpha=0.858$; Gardening $\alpha=0.872$ ), and all four factors (Individual Engagement $\alpha=0.864$; Social Engagement $\alpha=0.797$; Planting $\alpha=0.876$; Wildlife $\alpha=0.781$ ).

\subsection{Study Two}

\subsubsection{Test-Retest Reliability}

Cronbach's Alpha was used to examine internal reliability changes of the scale and its subscales. A Cronbach's alpha of the retest data that was more than 0.2 lower than the initial data would indicate significant measurement error [54]. The data from the second study showed that all subscales had high reliability and did not differ more than 0.2 from the initial data reliability, as shown in Table 4 . 
Table 4. Cronbach's alpha at baseline and retest, as well as their differences; Pearson's r test-retest correlation coefficients.

\begin{tabular}{ccccc}
\hline Scale & Test $\alpha$ & Retest $\alpha$ & Difference & Test-Retest Correlation \\
\hline ProCoBS & 0.893 & 0.908 & +0.010 & $0.851^{* *}$ \\
Civil Action & 0.858 & 0.861 & +0.003 & $0.765^{* *}$ \\
Gardening & 0.872 & 0.883 & +0.011 & $0.849^{* *}$ \\
\hline Factor & & & & \\
\hline Individual Engagement & 0.864 & 0.785 & -0.079 & $0.704^{* *}$ \\
Social Engagement & 0.797 & 0.783 & -0.059 & $0.675^{* *}$ \\
Plants & 0.876 & 0.890 & +0.014 & $0.794^{* *}$ \\
Wildlife & 0.781 & 0.785 & +0.004 & $0.824^{* *}$ \\
\hline
\end{tabular}

Notes: ${ }^{* *}$ Correlation is significant at the 0.001 level (2-tailed).

The combined scale, the separate scales, and the subscales from the retest data were correlated with the scales from the study one data. All scales and subscales were significantly correlated between the initial data collection and the retest $(p<0.001)$ with almost all $r \geq 0.7$, as shown in Table 4 .

\subsubsection{Validity}

Pearson's r was calculated between related constructs and the scale for the ProCoBS and the separate Civil Action and Gardening scales. All of the scales were significantly $(p<0.001)$ and positively correlated with all of the measured constructs, $r$ ranged from 0.260 to 0.651 , as shown in Table 5 . Furthermore, all of the factors were positively correlated with the validation constructs, as shown in Table 6.

Table 5. Pearson's r correlation matrix of the scale and subscales with the validation measures.

\begin{tabular}{cccc}
\hline Validation Construct & Full ProCoBS & Civil Action & Gardening \\
\hline Self-efficacy & $0.306^{* *}$ & $0.280^{* *}$ & $0.304^{* *}$ \\
Wellbeing & $0.303^{* *}$ & $0.284^{* *}$ & $0.270^{* *}$ \\
Pro-environmental behaviour & $0.563^{* *}$ & $0.587^{* *}$ & $0.529^{* *}$ \\
New environmental paradigm & $0.296^{* *}$ & $0.286^{* *}$ & $0.295^{* *}$ \\
Nature relatedness & $0.645^{* *}$ & $0.570^{* *}$ & $0.608^{* *}$ \\
Inclusion of nature in self & $0.520^{* *}$ & $0.414^{* *}$ & $0.496^{* *}$ \\
\hline
\end{tabular}

Notes: ${ }^{* *}$ Correlation is significant at the 0.001 level (2-tailed).

Table 6. Pearson's r correlation matrix of the factors with the validation measures.

\begin{tabular}{ccccc}
\hline Validation Construct & Individual Engagement & Planting & Organised Engagement & Wildlife \\
\hline Self-efficacy & $0.307^{* *}$ & $0.302^{* *}$ & $0.188^{* *}$ & $0.254^{* *}$ \\
Wellbeing & $0.271^{* *}$ & $0.211^{* *}$ & $0.254^{* *}$ & $0.276^{* *}$ \\
Pro-environmental behaviour & $0.594^{* *}$ & $0.475^{* *}$ & $0.445^{* *}$ & $0.491^{* *}$ \\
New environmental paradigm & $0.337^{* *}$ & $0.227^{* *}$ & $0.153^{* *}$ & $0.305^{* *}$ \\
Nature relatedness & $0.564^{* *}$ & $0.567^{* *}$ & $0.476^{* *}$ & $0.541^{* *}$ \\
Inclusion of nature in self & $0.402^{* *}$ & $0.437^{* *}$ & $0.359^{* *}$ & $0.461^{* *}$ \\
\hline
\end{tabular}

Notes: ${ }^{* *}$ Correlation is significant at the 0.001 level (2-tailed).

\subsubsection{Short Form}

Data from study one were used to develop a short form of the 18-item ProCoBS scale. In the first step, we examined the SME data and removed the poorest performing item from each of the four factors of the ProCoBS. We then computed item-total correlations, removing all items with $r$-values $<0.4$, leading to the removal of three Civil Action items. One item pair correlated at $\geq 0.8$ ("I plant pollinator-friendly plants" and "I plant plants with different flowering seasons"), the item with the lower SME score was removed. After these items were removed, PAF was performed on the 
remaining items. A Promax rotation with Kaiser normalisation extracted two factors with Eigenvalues $\geq 1$, also supported by the scatter plot. The same threshold of 0.45 , used for the long form, was applied, leading to the removal of two Gardening items. PAF was performed on the resulting 8-item ProCoBS short form (ProCoBS-SF). There were two factors with eigenvalues $\geq 1$ and the scree plot suggested two factors. All items had a factor loading of $\geq 0.45$ and no cross-loading $\geq 0.45$. The Civil Action and Gardening items separated into one factor each, as shown in Table 7.

Table 7. Pattern matrix of rotated factor loadings for the ProCoBS Short Form (showing all factor loadings $\geq 0.45$ ).

\begin{tabular}{|c|c|c|}
\hline Behaviour & Civil Action & Gardening \\
\hline I get in touch with local authorities on nature conservation issues & 0.864 & \\
\hline When I see litter, I pick it up & 0.728 & \\
\hline I vote for parties/candidates with strong pro-nature conservation policies in elections & 0.676 & \\
\hline $\begin{array}{l}\text { I vote for nature or wildlife conservation-friendly legislation in local or national } \\
\text { referendums/votes/etc. }\end{array}$ & 0.620 & \\
\hline I maintain plants with berries/fruits & & 0.829 \\
\hline I add log piles or other materials that can be used as a home/shelter by wildlife & & 0.660 \\
\hline I plant pollinator-friendly plants & & 0.647 \\
\hline I provide food for wild animals such as birds & & 0.522 \\
\hline
\end{tabular}

Cronbach's alpha was calculated to examine the internal reliability of the ProCoBS-SF and its subscales. Reliability was high for the full short form $(\alpha=0.825)$ and both subscales (Civil Action-SF $\alpha=0.805$; Gardening-SF $\alpha=0.769$ ). The full short form and its subscales also showed reliable strong positive correlations with the long form and its subscales (ProCoBS-SF-ProCoBS $r=0.935, p<0.001$; Civil Actions-SF-Civil Actions $r=0.940, p<0.001$; Gardening-SF-Gardening $r=0.941, p<0.001$ ). Test-retest reliability was assessed with correlations between the data from study one and the data from study two, which suggested a good test-retest reliability (ProCoBS $r=0.793, p<0.001$; Civil Action $r=0.699, p<0.001$; Gardening $r=0.827, p<0.001$ ). The short form and short form subscale scores from study two were also correlated with the same validation constructs as the long form. All of the correlations were significant at the 0.001 level and the Pearson's $r$ sizes were similar to the ones of the long form, as shown in Table 8.

Table 8. Pearson's r correlation matrix between the short form (Full, Civil Action, Gardening-from study two data) with the validation measures.

\begin{tabular}{clcc}
\hline Validation Construct & Full SF & Civil Action SF & Gardening SF \\
\hline Self-efficacy & $0.348^{* *}$ & $0.299^{* *}$ & $0.302^{* *}$ \\
Wellbeing & $0.290^{* *}$ & $0.241^{* *}$ & $0.272^{* *}$ \\
Pro-environmental behaviour & $0.609^{* *}$ & $0.605^{* *}$ & $0.485^{* *}$ \\
New environmental paradigm & $0.371^{* *}$ & $0.379^{* *}$ & $0.274^{* *}$ \\
Nature relatedness & $0.652^{* *}$ & $0.570^{* *}$ & $0.599^{* *}$ \\
Inclusion of nature in self & $0.480^{* *}$ & $0.403^{* *}$ & $0.470^{* *}$ \\
\hline
\end{tabular}

Notes: ${ }^{* *}$ Correlation is significant at the 0.001 level (2-tailed).

\subsection{Study Three}

Using the data from study three, a Confirmatory Factor Analysis was conducted on the 8-item short form of the ProCoBS to test the proposed two factor structure. Kaiser-Meyer-Olkin (0.839) indicated that sampling was adequate [63], and Bartlett's test indicated that the factorability of the correlation matrix was good $\left(X^{2}=4582.583, p<0.001\right)$. This, alongside a sample size greater than 200 ( $N=1298$ ), led to the Maximum Likelihood method being carried out. The item "When I see litter, I pick it up" had the lowest factor loading of $\mathrm{R}^{2}=0.172$. Hu and Bentler [64] recommend overall fit $(p>$ 0.05 ) absolute fit (SRMR $\leq 0.08$, RMSEA $\leq 0.06)$ and incremental fit (NFI $\geq 0.95, \mathrm{CFI} \geq 0.95$, TLI $\geq 0.95)$. Fit indices were mostly within tolerance, overall fit $\left(X^{2}=238.071, p<0.001\right)$ absolute fit (SRMR $=0.073$, 
RMSEA $=0.094)$ and incremental fit $(\mathrm{NFI}=0.948, \mathrm{CFI}=0.952, \mathrm{TLI}=0.929)$. However, modification indices indicate that if "I vote for nature or wildlife conservation-friendly legislation in local or national referendums/votes/etc." and "I vote for parties/candidates with strong pro-nature conservation policies in elections" were covaried, then the fit indices were improved to all fit within the threshold overall fit $\left(X^{2}=90.114, p<0.001\right)$, absolute fit (SRMR $=0.031$, RMSEA $\left.=0.056\right)$, and incremental fit $(\mathrm{NFI}=0.980$, $\mathrm{CFI}=0.984, \mathrm{TLI}=0.975)$.

\section{Discussion}

The ProCoBS and the ProCoBS-SF were developed and validated using standard psychometric procedures. The results demonstrated that both the full scale (with its subscales) as well as the short form scale have high internal reliability and test-retest reliability. Validation analyses found that both the full scale and the short form scale are correlated to constructs that were hypothesised to be related to pro-nature conservation behaviours, providing strong support for the construct validity of the scale. Furthermore, analyses distinguished four factors of pro-nature conservation behaviours. Furthermore, a Confirmatory Factor Analysis of the ProCoBS-SF indicated a good-fit with the two-factor structure found in the Exploratory Factor Analysis, thus indicating that the proposed factor structure was psychometrically robust.

In the full scale, civil actions, which, unlike the gardening behaviours, were not tied to greenspaces, were split into two factors: "Individual Engagement" and "Organised Engagement". Both of these consisted of behaviours that may be similar to "non-activist behaviours in the public sphere" in pro-environmental behaviours [26]. This divide between behaviours may reflect a divide also found in general environmental behaviour. Kaiser and Wilson [27] theorised that found differences may be explained by differences in difficulties between behaviours. Engaging in behaviours that are organised by the individual may represent different challenges than participating in a pre-organised activity. This separation is supported by the difference in correlation sizes between the factors and the self-efficacy measures: The Individual Engagement items were more highly correlated with self-efficacy than the Organised Engagement items.

Behaviours that were grouped under Individual Engagement were behaviours that may require individual organisation and motivation. A large proportion of the behaviours in this factor were political behaviours, which related to opportunities whereby citizens in a democracy can influence legislation and policies surrounding nature conservation. In general, political participation is an important means for citizens to communicate their views to the government and includes behaviours such as voting and communicating with officials [65]. Both of these behaviours grouped in the Individual Engagement factor. Voting behaviour, specifically, has also been included in existing research on conservation-related behaviours [5]. In pro-environmental behaviours, support for public policies is an important part of non-activist behaviours in the public sphere [26]. Interestingly, picking up litter fell into this factor as well, even though it is not political participation. Furthermore, and in contrast to the above, the behaviour of taking part in clean-up events fell into the Social Engagement factor. This specific difference shines a light on the difference between the two factors found within Civil Actions. While both behaviours have the same objective outcome (removal of litter), litter picking is coming from a place of individual effort and organisation, whereas taking part in a clean-up is attending an event organised by someone else. However, the item "I attend local council/local authority meetings about nature conservation issues" does not seem to be fully in line with the other items in this factor. Such meetings are pre-organised activities that individuals can participate in. More research is therefore required to explore how and why this behaviour in particular differs from other pre-organised activities, and in which way it may present different challenges than other similar behaviours in the "Organised Engagement" factor.

The majority of items in the Organised Engagement factor take place in the public sphere but are less directly related to political action. Instead these items rather focus on the social aspects of citizenship. Behaviours, such as petitioning, are also included in some measures of general pro-environmental 
behaviours, where they are classed under environmental citizenship [26]. The other items in this factor relate more to practical volunteering within a conservation framework. Volunteering within the more general environmental sector has been examined and found to be related to positive well-being outcomes [66], as well as the more specific volunteering with a conservation organisation [49].

In gardening behaviours there were also two factors: "Planting" and "Wildlife". "Planting" refers to which type of plants an individual maintains in their garden, which includes planting pollinator-friendly species, a behaviour which has a high importance considering that pollinators are particularly affected by the biodiversity decline $[7,8]$. Pollinators play an important role for society in providing an ecosystem service crucial to food production, with more than $87 \%$ of flowering plant species being pollinated by animals [67]. The behaviour of maintaining plants with different flowering seasons can further support insect diversity in gardens and/or on agricultural land. For example, adding late-season flowering plants to the fields of early-season flowering crops has been shown to have a positive influence on bumble bee density [68]. In addition to this, the behaviour of planting native plants has benefits beyond supporting native plant biodiversity. In Australia and the USA, native plants in domestic gardens have been found to increase bird and butterfly diversity $[69,70]$.

Behaviours in the "Wildlife" factor relate to the creation of a less artificially maintained garden and the introduction of features that can provide resources and/or habitats for wild plants and animals. Leaving an unmaintained area, or "wildflower patch" is a widely recommended action and has been used as an indicator of conservation friendly behaviour in past research [5]. Another behaviour in this factor is feeding birds. In total, $48 \%$ of UK households provide food for wild birds [71]. This behaviour has been shown to have a positive effect on avian diversity and abundance [72]. In addition to the ecological impact, bird feeding has been shown to be related to connection to nature and well-being, specifically relaxation [73].

To test the validity of the ProCoBS we correlated the scale with pro-environmental behaviours. As predicted, the full scale and its subscales, as well as the short form and its subscales, were significantly positively correlated with pro-environmental behaviours. While little is known about which specific pro-environmental behaviours and pro-conservation behaviours are related to each other, there often seems to be an overlap, and participation in wider environmental activities has been linked to wildlife-friendly gardening [74]. However, existing research [19] suggests that pro-conservation behaviours and pro-environmental behaviours remain separate constructs. Furthermore, we predicted that pro-conservation behaviours would be related to similar psychological concepts as pro-environmental behaviours. Especially since the two scales we employed to measure nature connectedness had a strong [75], significant correlation with the ProCoBS, which supports that prediction. This is also in line with findings from other studies that people with higher connectedness to nature are more likely to engage in pro-nature conservation practices, such as adding wild-flower patches to their gardens or considering biodiversity in their voting intentions [5]. Pro-nature conservation gardening directly operationalises the compassion pathway to nature connectedness [44] and may also provide meaningful experiences with nature, thus improving nature connectedness [76,77].

In order to prevent a further acceleration of biodiversity loss and its consequences, a better understanding of which behaviours have a positive impact on biodiversity, and how the general public can be encouraged to engage in those behaviours, is needed. The ProCoBS constitutes a crucial tool for research on pro-nature conservation behaviours. Measuring tools for behaviours can be used to examine what influences those behaviours and to develop and evaluate communications and interventions aimed towards them [24].

The ProCoBS is a self-report measure. Self-report measures have the advantage of being easy to administer at a low cost, thus providing an ideal tool for large scale research and citizen science studies [24]. The developed short form can facilitate engagement with the scale from conservation organisations who wish to use the scale in evaluating their projects in time-pressured settings. However, researchers should be aware of possible inaccuracies in self-report measures. Inaccuracies can be caused, for example, by over-reporting or the differing perceptions between participants of what the 
frequency markers, such as "often", mean $[78,79]$. Apart from the limitations of self-report measures, a possible limitation of the ProCoBS specifically might be that it was developed with the UK and central Europe in mind. All of the SMEs were UK based (with only one originating from mainland Europe) and all of the participants who took the scales were from the UK. Nevertheless, the political participation items might be applicable to other countries with similar democratic governments and the social engagement items may relate to all societies with similar social and cultural structures. However, it is likely that the gardening items might be more specific to the UK and central European ecosystem. Our methodology could be adopted in developing equivalent measures in heterogenous ecosystems. More research, with a greater international reach, should therefore be undertaken to explore how the ProCoBS performs in different geographical and cultural settings. The ProCoBS may be used as a complete scale for people who have access to a garden, but, when focusing on a sample where some people have access while others do not, the two subscales should be used separately. This makes the scale more adaptable and suitable for a larger socio-economic group, which could be a strength; however, it may also prove to be a limitation. Further research on whether this scale should be used as one scale, or whether the two subscales may be more useful as separate scales is needed.

The similarities and differences between pro-nature conservation behaviours and pro-environmental behaviours also needs to be further examined. Some parts of the wide base of underlying theoretical framework of pro-environmental behaviours may be applicable to pro-nature conservation behaviours, while others may not be a good fit. For example, Stern's [26] differentiation between public and private sphere behaviours was used in the development of this scale.

Future research should employ the ProCoBS in different contexts to further establish its validity and reliability. The ProCoBS can be used to explore the extent of the Value-Action gap for pro-nature conservation behaviours and ways to close this gap. Some of the constructs used for the validation of the scale, such as connectedness to nature, are likely to be important predictors of pro-nature conservation behaviours. Research on the different predictors of pro-nature conservation behaviours and their interaction is crucial in understanding and encouraging these behaviours as we move to mitigate and manage species loss in our changing world.

\section{Conclusions}

Biodiversity loss will have similar devastating global consequences to climate change, yet behaviours to counter biodiversity loss are, by far, less studied than behaviours relating to mitigating climate change. The ProCoBS constitutes a reliable and valid measurement tool for active behaviours supporting nature conservation. The results show that these pro-nature conservation behaviours have several related factors and include a wide variety of actions from gardening to political behaviours. As the first scale of its type, the measure can have international impact, given its valuable potential uses in research as well as in practical conservation work. However, although the scale is likely to be relevant more widely, cross-cultural studies, country specific validations, and possible modification for use outside of the UK are needed. The ProCoBS facilitates the examination of underlying motives and factors that determine pro-nature conservation behaviours and allows the intervention and communication programmes encouraging these behaviours to be evaluated. The short form, especially, will be useful to researchers and conservation practitioners who want to employ it in large-scale surveys alongside measurements of other psychological and behavioural constructs, or as a quick evaluation tool to assess the effectiveness of projects and interventions. Its utility is evidenced by its adoption by the National Trust in a large-scale survey in the UK $[80,81]$, as well as through its inclusion in the People and Nature survey by Natural England [82]. These surveys gather evidence and allow population trends to be observed regarding pro-nature conservation behaviours and attitudes towards the natural environment. Furthermore, the People and Nature survey directly informs policy for the UK Department for Environment, Food, and Rural Affairs (Defra) and contributes to the outcome indicator framework for their 25 Year Environment Plan. 
Author Contributions: Concept of PRoCoBS, M.R. Survey design and methods L.B., E.J.N.S., M.S., and M.R. Data analysis was conducted by L.B., E.J.N.S., and M.B.S. Manuscript writing, editing, and review was conducted by L.B., E.J.N.S., M.S., M.R., and M.B.S. All authors contributed critically to the drafts and gave final approval for the submission of this article. All authors have read and agreed to the published version of the manuscript.

Funding: This research received no external funding.

Acknowledgments: The authors would like to acknowledge the Wildlife Trusts for their support in contacting experts in the field during the SME Review stage of the study. Raw data are from YouGov Plc. Total sample size was 2096 adults, 16+ years of age. Fieldwork was undertaken between 29 July to 30 July 2019. The survey was carried out online. The data have been weighted and are representative of all UK adults 16+ years of age.

Conflicts of Interest: The authors declare no conflict of interest.

\section{Appendix A. SME Questionnaire}

Definition: We define a pro-nature conservation behaviour as a positive action that has impact on local wildlife (rather than a positive inaction that has an indirect impact on wildlife conservation via reduction of e.g., the carbon footprint, water use, etc.).

Therefore, items that you might consider important for nature conservation, such as reducing car use or meat consumption are not present on this list. Research shows that people regard these behaviours as different from the more pro-active nature conservation behaviours. For now, to facilitate review, the items are put under headlines depending on the category of the behaviour-these headlines will not be shown in the final questionnaire. You will see that some items are marked as "Reverse coded". This means that the behaviour in the item has a negative impact on nature conservation, and the item will therefore be graded in reverse to other items to reflect this.

Before you start, please let us know what area of conservation you are an expert in and how. Are you an academic in conservation science, do you manage a reserve for a conservation organisation, etc.?

\section{Appendix A.1. At Home and in Nature}

Please indicate for each item whether, considering our definition of pro-nature conservation behaviours, you believe that the item belongs on an impact based questionnaire that assesses those behaviours.

Behaviour
I provide food for animal
I provide water for animal
I pick up litter
I move insects rather than killing them when finding them at home
When walking in nature I try to avoid disturbing wildlife
I move small animals when finding them on a road
I avoid using insect repellents

\section{Appendix A.2. Civil Action}

Please indicate for each item whether, considering our definition of pro-nature conservation behaviours, you believe that the item belongs on an impact based questionnaire that assesses those behaviours. 


\begin{tabular}{|c|c|c|c|}
\hline Behaviour & Yes & No & I Do Not Know \\
\hline \multicolumn{4}{|l|}{ I donate money to a conservation organisation } \\
\hline \multicolumn{4}{|l|}{ I volunteer with a conservation organisation in the area of fund raising } \\
\hline \multicolumn{4}{|l|}{$\begin{array}{l}\text { I volunteer with a conservation organisation in the area of land } \\
\text { management work }\end{array}$} \\
\hline \multicolumn{4}{|l|}{$\begin{array}{l}\text { I volunteer with a conservation organisation in the area of surveying (e.g., } \\
\text { garden bird watch/bio-blitz/etc.) }\end{array}$} \\
\hline \multicolumn{4}{|l|}{$\begin{array}{l}\text { I volunteer with a conservation organisation in another area not } \\
\text { mentioned above }\end{array}$} \\
\hline \multicolumn{4}{|l|}{ I participate in clean-up events } \\
\hline \multicolumn{4}{|l|}{ I hold a membership with a conservation organisation } \\
\hline \multicolumn{4}{|l|}{ I talk to other people about the importance of wildlife conservation } \\
\hline \multicolumn{4}{|l|}{ I join activist activities (e.g., demonstrations) } \\
\hline \multicolumn{4}{|l|}{$\begin{array}{l}\text { I support conservation friendly legislation (e.g., for agriculture, hunting, etc.) } \\
\text { by voting for them when given the opportunity in local or national } \\
\text { referendums/votes/etc. }\end{array}$} \\
\hline \multicolumn{4}{|l|}{ I attend local council/local authority meetings about conservation issues } \\
\hline \multicolumn{4}{|l|}{ I sign petitions supporting conservation efforts } \\
\hline \multicolumn{4}{|l|}{ I get in touch with local authorities about conservation issues and solutions } \\
\hline \multicolumn{4}{|l|}{ I share posts and articles about conservation on social media } \\
\hline I vote for parties/candidates with strong pro-conservation policies in elections & & & \\
\hline $\begin{array}{l}\text { I go to talks/watch documentaries about nature conservation issues or I } \\
\text { otherwise educate myself on the topic }\end{array}$ & & & \\
\hline
\end{tabular}

\section{Appendix A.3. Gardening/Land Management Behaviours}

Gardening behaviour items will only be answered by people who indicated that they have access to a garden or are a landowner. Some of these items are feature based, others are behaviour based- this will be reflected in the answer format. All items will be specifically linked to behaviours in the garden/in land management. Please indicate for each item whether, considering our definition of pro-nature conservation behaviours, you believe that the item belongs on an impact based questionnaire that assesses those behaviours. 


Behaviour
I plant pollinator friendly plants
I plant plants with different flowering seasons
I avoid using insecticides
I use synthetic fertilizer (reverse coded)
I use weed killer (reverse coded)
I Do Not Know
I keep my lawn neat and tidy (reverse coded)
I leave an undisturbed/unmaintained area for wildlife
I maintain plants with berries/fruits
I plant native plants
I plant exotic plants (reverse coded)
I rotate the annual plants and crops I sow each year

\section{References}

1. IPCC. IPCC Climate Change 2014 Synthesis Report Summary Chapter for Policymakers; IPCC: Geneva, Switzerland, 2014.

2. Bongaarts, J. Summary for policymakers of the global assessment report on biodiversity and ecosystem services of the Intergovernmental Science-Policy Platform on Biodiversity and Ecosystem Services. Popul. Dev. Rev. 2019, 45, 680-681. [CrossRef]

3. Legagneux, P.; Casajus, N.; Cazelles, K.; Chevallier, C.; Chevrinais, M.; Guéry, L.; Jacquet, C.; Jaffré, M.; Naud, M.-J.; Noisette, F.; et al. Our house is burning: Discrepancy in climate change vs. biodiversity coverage in the media as compared to scientific literature. Front. Ecol. Evol. 2018, 5, 5. [CrossRef]

4. Ceballos, G.; Ehrlich, P.R.; Dirzo, R. Biological annihilation via the ongoing sixth mass extinction signaled by vertebrate population losses and declines. Proc. Natl. Acad. Sci. USA 2017, 114, E6089-E6096. [CrossRef]

5. Prévot, A.-C.; Cheval, H.; Raymond, R.; Cosquer, A. Routine experiences of nature in cities can increase personal commitment toward biodiversity conservation. Biol. Conserv. 2018, 226, 1-8. [CrossRef]

6. WWF. Living Planet Report-2018: Aiming Higher; WWF: Gland, Switzerland, 2018; ISBN 978-2-940529-90-2.

7. Hallmann, C.A.; Sorg, M.; Jongejans, E.; Siepel, H.; Hofland, N.; Schwan, H.; Stenmans, W.; Müller, A.; Sumser, H.; Hörren, T.; et al. More than 75 percent decline over 27 years in total flying insect biomass in protected areas. PLoS ONE 2017, 12, e0185809. [CrossRef] [PubMed]

8. Oliver, T.H.; Isaac, N.J.B.; August, T.A.; Woodcock, A.B.; Roy, D.B.; Bullock, J.M. Declining resilience of ecosystem functions under biodiversity loss. Nat. Commun. 2015, 6, 10122. [CrossRef]

9. Díaz, S.; Fargione, J.; Chapin, F.S.; Tilman, D. Biodiversity loss threatens human well-being. PLoS Biol. 2006, 4, e277. [CrossRef] [PubMed]

10. Ceballos, G.; Ehrlich, P.R.; Barnosky, A.D.; Garcia, A.; Pringle, R.M.; Palmer, T. Accelerated modern human-induced species losses: Entering the sixth mass extinction. Sci. Adv. 2015, 1, e1400253. [CrossRef]

11. McDonald, R.; Kareiva, P.; Forman, R.T.T. The implications of current and future urbanization for global protected areas and biodiversity conservation. Biol. Conserv. 2008, 141, 1695-1703. [CrossRef]

12. Maxwell, S.L.; Fuller, R.; Brooks, T.M.; Watson, J. Biodiversity: The ravages of guns, nets and bulldozers. Nature 2016, 536, 143-145. [CrossRef]

13. Noortgaete, F.V.D.; De Tavernier, J. Affected by nature: A hermeneutical transformation of environmental ethics. Zygon(r) 2014, 49, 572-592. [CrossRef]

14. Kollmuss, A.; Agyeman, J. Mind the gap: Why do people act environmentally and what are the barriers to pro-environmental behavior? Environ. Educ. Res. 2002, 8, 239-260. [CrossRef] 
15. Saunders, C.D.; Brook, A.T.; Myers, O.E. Using psychology to save biodiversity and human well-being. Conserv. Biol. 2006, 20, 702-705. [CrossRef] [PubMed]

16. Markle, G. Pro-environmental behavior: Does it matter how it's measured? Development and validation of the pro-environmental behavior scale (PEBS). Hum. Ecol. 2013, 41, 905-914. [CrossRef]

17. Christmas, S.; Wright, L.; Morris, L.; Watson, A.; Miskelly, C. Engaging People in Biodiversity Issues; Defra-Department for Environment, Food and Rural Affairs: London, UK, 2013.

18. Hughes, J.; Richardson, M.; Lumber, R. Evaluating connection to nature and the relationship with conservation behaviour in children. J. Nat. Conserv. 2018, 45, 11-19. [CrossRef]

19. Martin, L.; White, M.P.; Hunt, A.; Richardson, M.; Pahl, S.; Burt, J. Nature contact, nature connectedness and associations with health, wellbeing and pro-environmental behaviours. J. Environ. Psychol. 2020, 68, 101389. [CrossRef]

20. Richardson, M.; Hunt, A.; Hinds, J.; Bragg, R.; Fido, D.; Petronzi, D.; Barbett, L.; Clitherow, T.J.; White, M. A measure of nature connectedness for children and adults: Validation, performance, and insights. Sustainability 2019, 11, 3250. [CrossRef]

21. Richardson, M.; Cormack, A.; McRobert, L.; Underhill, R. 30 Days wild: Development and evaluation of a large-scale nature engagement campaign to improve well-being. PLoS ONE 2016, 11, e0149777. [CrossRef]

22. Deguines, N.; Princé, K.; Prévot, A.-C.; Fontaine, B. Assessing the emergence of pro-biodiversity practices in citizen scientists of a backyard butterfly survey. Sci. Total Environ. 2020, 716, 136842. [CrossRef]

23. Massingham, E.; Fuller, R.; Dean, A.J. Pathways between contrasting ecotourism experiences and conservation engagement. Biodivers. Conserv. 2019, 28, 827-845. [CrossRef]

24. Lange, F.; Dewitte, S. Measuring pro-environmental behavior: Review and recommendations. J. Environ. Psychol. 2019, 63, 92-100. [CrossRef]

25. Barr, S.; Gilg, A.W.; Ford, N. The household energy gap: Examining the divide between habitual- and purchase-related conservation behaviours. Energy Policy 2005, 33, 1425-1444. [CrossRef]

26. Stern, P.C. New environmental theories: Toward a coherent theory of environmentally significant behavior. J. Soc. Issues 2000, 56, 407-424. [CrossRef]

27. Kaiser, F.G.; Wilson, M. Goal-directed conservation behavior: The specific composition of a general performance. Pers. Individ. Differ. 2004, 36, 1531-1544. [CrossRef]

28. Kaiser, F.G.; Wölfing, S.; Fuhrer, U. Environmental attitude and ecological behaviour. J. Environ. Psychol. 1999, 19, 1-19. [CrossRef]

29. Goddard, M.; Dougill, A.J.; Benton, T.G. Scaling up from gardens: Biodiversity conservation in urban environments. Trends Ecol. Evol. 2010, 25, 90-98. [CrossRef]

30. Van Heezik, Y.; Dickinson, K.; Freeman, C. Closing the gap: Communicating to change gardening practices in support of native biodiversity in urban private gardens. Ecol. Soc. 2012, 17. [CrossRef]

31. Gaston, K.J.; Smith, R.M.; Thompson, K.; Warren, P.H. Urban domestic gardens (II): Experimental tests of methods for increasing biodiversity. Biodivers. Conserv. 2005, 14, 395-413. [CrossRef]

32. The Wildlife Trusts Help Wildlife at Home. Available online: https://www.wildlifetrusts.org/actions (accessed on 17 February 2020).

33. Bullard, R.D.; Johnson, G.S. Environmentalism and public policy: Environmental justice: Grassroots activism and its impact on public policy decision making. J. Soc. Issues 2000, 56, 555-578. [CrossRef]

34. Koger, S.M.; Winter, D.D. The Psychology of Environmental Problems; Psychology Press: East Sussex, UK, 2014; ISBN 9781410610737.

35. Vancouver, J.B.; More, K.M.; Yoder, R.J. Self-efficacy and resource allocation: Support for a nonmonotonic, discontinuous model. J. Appl. Psychol. 2008, 93, 35-47. [CrossRef]

36. Bandura, A. Social Cognitive Theory and Exercise of Control over HIV Infection; Springer Science and Business Media LLC: Berlin, Germany, 1994; pp. 25-59.

37. Bandura, A. Self-efficacy: Toward a unifying theory of behavioral change. Adv. Behav. Res. Ther. 1978, 1, 139-161. [CrossRef]

38. Clayton, S.; Prévot, A.-C.; Germain, L.; Saint-Jalme, M. Public support for biodiversity after a zoo visit: Environmental concern, conservation knowledge, and self-efficacy. Curator Mus. J. 2017, 60, 87-100. [CrossRef]

39. Mayer, F.; Frantz, C.M. The connectedness to nature scale: A measure of individuals' feeling in community with nature. J. Environ. Psychol. 2004, 24, 503-515. [CrossRef] 
40. Nisbet, E.K.; Zelenski, J. The NR-6: A new brief measure of nature relatedness. Front. Psychol. $2013,4,4$. [CrossRef] [PubMed]

41. Otto, S.; Pensini, P. Nature-based environmental education of children: Environmental knowledge and connectedness to nature, together, are related to ecological behaviour. Glob. Environ. Chang. 2017, 47, 88-94. [CrossRef]

42. Mackay, C.M.; Schmitt, M.T. Do people who feel connected to nature do more to protect it? A meta-analysis. J. Environ. Psychol. 2019, 65. [CrossRef]

43. Whitburn, J.; Linklater, W.; Abrahamse, W. Meta-analysis of human connection to nature and proenvironmental behavior. Conserv. Boil. 2019, 34, 180-193. [CrossRef]

44. Lumber, R.; Richardson, M.; Sheffield, D. Beyond knowing nature: Contact, emotion, compassion, meaning, and beauty are pathways to nature connection. PLOS ONE 2017, 12, e0177186. [CrossRef]

45. Dunlap, R.E.; Van Liere, K.D.; Mertig, A.G.; Jones, R.E. New trends in measuring environmental attitudes: Measuring endorsement of the new ecological paradigm: A revised NEP scale. J. Soc. Issues 2000, 56, 425-442. [CrossRef]

46. Dunlap, R.E.; Van Liere, K.D. The "new environmental paradigm". J. Environ. Educ. 1978, 9, 10-19. [CrossRef]

47. Davis, J.L.; Le, B.; Coy, A. Building a model of commitment to the natural environment to predict ecological behavior and willingness to sacrifice. J. Environ. Psychol. 2011, 31, 257-265. [CrossRef]

48. Gkargkavouzi, A.; Halkos, G.; Matsiori, S. A multi-dimensional measure of environmental behavior: Exploring the predictive power of connectedness to nature, ecological worldview and environmental concern. Soc. Indic. Res. 2018, 143, 859-879. [CrossRef]

49. Rogerson, M.; Barton, J.; Bragg, R.; Pretty, J. The Health and Wellbeing Impacts of Volunteering with the Wildlife Trusts; University of Essex: Essex, UK, 2017.

50. Pritchard, A.; Richardson, M.; Sheffield, D.; McEwan, K. The relationship between nature connectedness and eudaimonic well-being: A meta-analysis. J. Happiness Stud. 2019, 21, 1145-1167. [CrossRef]

51. Lee, J.; Park, B.-J.; Tsunetsugu, Y.; Ohira, T.; Kagawa, T.; Miyazaki, Y. Effect of forest bathing on physiological and psychological responses in young Japanese male subjects. Public Health 2011, 125, 93-100. [CrossRef] [PubMed]

52. DeVellis, R.F. Scale Development: Theory and Applications; SAGE: New York, NY, USA, 2012; Volume 26.

53. Lawshe, C.H. A quantitative approach to content validity. Pers. Psychol. 1975, 28, 563-575. [CrossRef]

54. Nunnally, J.; Bernstein, I. Psychometric Theory, 3rd ed.; McGraw-Hill: New York, NY, USA, 1994.

55. Comrey, A.L. Factor-analytic methods of scale development in personality and clinical psychology. J. Consult. Clin. Psychol. 1988, 56, 754-761. [CrossRef]

56. Vagias, W. Likert-type scale response anchors. Clemson Int. Inst. Tour. 2006.

57. Schultz, P.W. The structure of environmental concern: Concern for self, other people, and the biosphere. J. Environ. Psychol. 2001, 21, 327-339. [CrossRef]

58. Geng, L.; Xu, J.; Ye, L.; Zhou, W.; Zhou, K. Connections with nature and environmental behaviors. PLoS ONE 2015, 10, e0127247. [CrossRef]

59. World Health Organization. Wellbeing Measures in Primary Health Care/the Depcare Project; WHO: Geneva Switzerland, 1998.

60. Schwarzer, R.; Jerusalem, M. Generalized self-efficacy scale. Meas. Health Psychol. 1995. [CrossRef]

61. Tabachnick, B.G.; Fidell, L.S. Using Multivariate Statistics, 6th ed.; Peason: New York, NY, USA, 2012; ISBN 0205849571.

62. Comrey, A.L.; Lee, H.B. A First Course in Factor Analysis, 2nd ed.; Psychology Press: New York, NY, USA, 1992; ISBN 0-8058-1062-5.

63. Field, A. Discovering Statistics Using IBM SPSS Statistics; SAGE: New York, NY, USA, 2013.

64. Hu, L.T.; Bentler, P.M. Cutoff criteria for fit indexes in covariance structure analysis: Conventional criteria versus new alternatives. Struct. Equ. Model. A Multidiscip. J. 1999, 6, 1-55. [CrossRef]

65. Uhlaner, C.J. Politics and participation. In International Encyclopedia of the Social \& Behavioral Sciences, 2nd ed.; Elsevier: Amsterdam, The Netherlands, 2015; ISBN 9780080970875.

66. Binder, M.; Blankenberg, A.-K. Environmental concerns, volunteering and subjective well-being: Antecedents and outcomes of environmental activism in Germany. Ecol. Econ. 2016, 124, 1-16. [CrossRef]

67. Ollerton, J.; Winfree, R.; Tarrant, S. How many flowering plants are pollinated by animals? Oikos 2011, 120, 321-326. [CrossRef] 
68. Rundlöf, M.; Persson, A.; Smith, H.G.; Bommarco, R. Late-season mass-flowering red clover increases bumble bee queen and male densities. Biol. Conserv. 2014, 172, 138-145. [CrossRef]

69. Burghardt, K.T.; Tallamy, D.W.; Shriver, W.G. Impact of native plants on bird and butterfly biodiversity in suburban landscapes. Conserv. Biol. 2009, 23, 219-224. [CrossRef] [PubMed]

70. Daniels, G.D.; Kirkpatrick, J. Does variation in garden characteristics influence the conservation of birds in suburbia? Biol. Conserv. 2006, 133, 326-335. [CrossRef]

71. Davies, Z.G.; Fuller, R.; Loram, A.; Irvine, K.N.; Sims, V.; Gaston, K.J. A national scale inventory of resource provision for biodiversity within domestic gardens. Biol. Conserv. 2009, 142, 761-771. [CrossRef]

72. Fuller, R.; Warren, P.H.; Armsworth, P.R.; Barbosa, O.; Gaston, K.J. Garden bird feeding predicts the structure of urban avian assemblages. Divers. Distrib. 2007, 14, 131-137. [CrossRef]

73. Cox, D.T.C.; Gaston, K.J. Urban bird feeding: Connecting people with nature. PLoS ONE 2016, 11, e0158717. [CrossRef]

74. Goddard, M.; Dougill, A.J.; Benton, T.G. Why garden for wildlife? Social and ecological drivers, motivations and barriers for biodiversity management in residential landscapes. Ecol. Econ. 2013, 86, 258-273. [CrossRef]

75. Cohen, J. Statistical Power Analsis of the Behavioral Sciences; Routledge: New York, NY, USA, 1988.

76. Clayton, S. Domesticated nature: Motivations for gardening and perceptions of environmental impact. J. Environ. Psychol. 2007, 27, 215-224. [CrossRef]

77. Shaw, A.; Miller, K.K.; Wescott, G. Wildlife gardening and connectedness to nature: Engaging the unengaged. Environ. Values 2013, 22, 483-502. [CrossRef]

78. Kormos, C.E.; Gifford, R. The validity of self-report measures of proenvironmental behavior: A meta-analytic review. J. Environ. Psychol. 2014, 40, 359-371. [CrossRef]

79. Barr, S. Factors influencing environmental attitudes and behaviors. Environ. Behav. 2007, 39, 435-473. [CrossRef]

80. Richardson, M.; Lumber, R.; Passmore, H.; Hunt, A.; Thomas, R.; Davies, N. Noticing Nature: The First Report in the Everyone Needs Nature Series. 2020. Available online: https:/nt.global.ssl.fastly.net/documents/ noticing-nature-report-feb-2020.pdf (accessed on 17 February 2020).

81. Richardson, M.; Passmore, H.; Barbett, L.; Lumber, R.; Thomas, R.; Hunt, A. The Green Care Code: How Nature Connectedness and Simple Activities Help Explain Pro-Nature Coservation Behaviours; Human Sciences Research Centre: London, UK, 2020.

82. Natural England. The People and Nature Survey for England-Questionnaire (PANS001); Natural England: York, UK, 2020. 